\title{
Genotype by environment interaction for post-weaning weight gain, scrotal circumference, and muscling score of composite beef cattle in different regions of Brazil
}

\author{
M.L. Santana Jr. ${ }^{1,2}$, J.P. Eler ${ }^{2}$, F.F. Cardoso ${ }^{3}$, L.G. Albuquerque ${ }^{4}$, \\ J.C.C. Balieiro ${ }^{2}$, R.J. Pereira ${ }^{1}$ and J.B.S. Ferraz ${ }^{2}$ \\ ${ }^{1}$ Grupo de Melhoramento Animal de Mato Grosso, \\ Instituto de Ciências Agrárias e Tecnológicas, \\ Universidade Federal de Mato Grosso, Campus Universitário de Rondonópolis, \\ Rondonópolis, MT, Brasil \\ ${ }^{2}$ Grupo de Melhoramento Animal e Biotecnologia, \\ Faculdade de Zootecnia e Engenharia de Alimentos, Universidade de São Paulo, \\ Pirassununga, SP, Brasil \\ ${ }^{3}$ Embrapa Pecuária Sul, Bagé, RS, Brasil \\ ${ }^{4}$ Departamento de Zootecnia, Faculdade de Ciências Agrárias e Veterinárias, \\ Universidade Estadual Paulista “Júlio de Mesquita Filho," Jaboticabal, SP, Brasil \\ Corresponding author: M.L. Santana Jr. \\ E-mail: 10mario@gmail.com
}

Genet. Mol. Res. 13 (2): 3048-3059 (2014)

Received December 10, 2012

Accepted July 2, 2013

Published April 17, 2014

DOI http://dx.doi.org/10.4238/2014.April.17.1

ABSTRACT. The objectives of this study were to characterize and
define homogenous production environments of composite beef
cattle in Brazil in terms of climatic and geographic variables by
using multivariate exploratory techniques; to evaluate the presence
of genotype by environment interaction (GxE) for post-weaning
weight gain (PWG), yearling scrotal circumference (SC), and yearling 
muscling (MUS). Hierarchical and nonhierarchical cluster analysis was used to group farms located in regions with similar environmental variables into clusters. Six clusters of farms were formed. The effect of sire-cluster interaction was tested by single-trait analysis. Genetic parameters were estimated by multi-trait analysis considering the same trait to be different in each cluster. The effect of sire-cluster interaction was significant $(\mathrm{P}<0.01)$ for PWG and MUS. Estimates of genetic correlations among clusters ranged from 0.31 to 0.93 for PWG, 0.64 to 0.89 for SC, and 0.18 to 0.80 for MUS. These results indicate the need for a genetic analysis on a regional basis or inclusion of the GxE effect in the statistical model to permit appropriate evaluation of the animals.

Key words: Cluster analysis; Genotype by environment interaction; Multibreed; Post-weaning gain; Temperature

\section{INTRODUCTION}

Brazil has a wide variety of beef cattle production systems, which in part reflects variations across the country in climatic, geographic, cultural, and economic factors (Eler et al., 2000; Toral et al., 2004). These factors can combine with different cattle genotypes, resulting in the so-called genotype by environment interaction $(\mathrm{GxE})$. The identification of GxE is relevant for genetic breeding programs since the animals suitable for a certain environment may have offspring that do not show the expected performance when raised in an environment different from that where the parents were selected. In the case of composite beef cattle, the breed composition of these animals provides a series of alternatives for the different Brazilian environments.

As proposed by Falconer (1952), the definition of the environment in which the analyzed trait is considered to be different is relevant for the study of GxE. Environments are usually distinguished according to country, state, or region (Tess et al., 1984; Bertrand et al., 1987; Lopes et al., 2008). A multivariate exploratory approach that groups specific regions into clusters based on their climatic, geographic characteristics, or both is a suitable alternative for defining environments as demonstrated by Weigel and Rekaya (2000) and Ravagnolo and Misztal (2002). In Brazil, this approach can be a rational strategy to reduce the number of environments to be studied.

The objectives of the present study were to characterize and define homogenous production environments in terms of climatic and geographic variables, by using multivariate exploratory techniques and to assess the presence of $\mathrm{GxE}$ for post-weaning weight gain (PWG), yearling scrotal circumference (SC), and yearling muscling (MUS) of composite beef cattle in Brazil.

\section{MATERIAL AND METHODS}

\section{Data}

The data used were from animals including purebred, crossbred, and composite beef cattle born between 1995 and 2008 on 33 farms located in 27 municipalities of the Brazilian states of Goiás (GO), Minas Gerais (MG), Mato Grosso do Sul (MS), Mato Grosso (MT), Pará (PA), Rio Grande do Sul (RS), and São Paulo (SP). These animals participate in the 
Montana Tropical ${ }^{\circledR}$ Composite Breeding Program, CFM-Leachman Pecuária Ltda. (Figure 1). To characterize the production environments, data representing 15 years (from 1994 to 2008) of climate observations (mean minimum and maximum annual temperature, and mean annual rainfall) and geographic (latitude, longitude, and altitude) were obtained from public weather stations (Agritempo, 2009) in each municipality where the farms were located.

On the basis of the original program of formation of composite beef cattle, i.e., the population used in the present study, the breeds were pre-grouped by Ferraz et al. (1999) according to their genetic similarity and general performance. This pre-grouping resulted in 4 large and general biological types, identified by the abbreviation NABC: group N (Bos indicus) represented by Zebu breeds, which mainly include Nellore (about $90 \%$ of this group), Tabapuã, Guzerat, and other breeds of African origin such as Boran and Tuli (Sanga breed); group A (Bos taurus) represented by breeds adapted to tropical climates, such as Afrikaner, Belmont Red, Bonsmara, Caracu, Romosinuano, and Senepol; group B (Bos taurus) represented by European breeds of British origin such as Aberdeen Angus, Red Angus, Devon, and Hereford; group C (Bos taurus) represented by European breeds of continental origin, such as Charolais, Gelbvieh, Brown Swiss, Simmental, Limousin, and others. In this population, an animal (composite beef cattle) should be composed of at least 3 different breeds, $12.5 \%$ of a breed adapted to the tropical environment and $25 \%$ of Zebu breed $(\mathrm{N})$ plus tropically adapted breeds (A). The maximum acceptable values are $37.5 \%$ group $\mathrm{N}, 87.5 \%$ group $\mathrm{A}, 100 \%$ group $\mathrm{N}$ plus $\mathrm{A}, 75 \%$ for groups $\mathrm{B}, \mathrm{C}$, and B plus C. Further information about the formation of the present composite beef cattle and distribution of farms throughout Brazil can be found in Santana et al. (2012).

The animals were kept on pasture with or without supplements in the dry season. In general, the pastures comprised Brachiaria brizantha. Especially in the Pantanal (Midwest) and Pampa (Southern Brazil), the native pasture plays an important role in animal feeding. All farms provided mineral supplements and some protein. Weight recordings were obtained at weaning and at yearling stage (approximately 205 and 420 days of age, respectively). The SC was measured by placing a tape around the scrotum at the point of maximum diameter. The MUS was evaluated by attributing visual scores of muscle mass ranging from 1 to 6 , with 6 assigned to most muscular animals. Scores were assigned to observations made within the contemporary groups. Records exceeding 3.5 standard deviations below or above the overall mean and contemporary groups containing fewer than 20 animals were excluded from the data set.

\section{Environmental characterization and definition of the number of environments}

The cluster analysis was performed by using the environmental variables of the municipalities where the farms were located as described in Santana et al. (2012). The Ward's hierarchical method of CLUSTER procedure (SAS, 2008) was used. The Ward's method forms clusters by maximizing within-clusters homogeneity (Khattree and Naik, 2000). The withingroup sum of squares was used as the measure of homogeneity. This hierarchical method resulted in ten clusters. The nonhierarchical cluster analysis solution was submitted to a nonhierarchical method to further refine the cluster solution. In the nonhierarchical method, each cluster (environment) to be formed should contain a minimum number of 1000 animals with valid records for each trait. Six clusters were identified on the basis of Euclidean distance by using the FASTCLUS procedure of the SAS program (2008). According to Zwald et al. (2003), this iterative method guarantees that the distances between observations in the same 
cluster will be smaller than the distances between observations of different clusters. The Rsquare and root mean square standard deviation (RMSSTD) were the parameters chosen to evaluate the clustering quality. The R-square assumes values from 0 to 1 , with 0 indicating no differences between clusters and 1 indicating the maximum difference between clusters. The $\mathrm{R}$-square should be close to 1 . The RMSSTD also assumes values between 0 and 1 and this value should be as low as possible, indicating homogeneity within the clusters formed.

\section{Estimation of genetic parameters for the study of genotype by environment interaction}

After the definition of clusters, hereafter called geoclimatic (GEO), only animals born to sires, which had progeny in at least 2 of these clusters, were maintained in the data set.

The statistical models for PWG, SC, and MUS included fixed effects of contemporary group (farm, year of birth, management group, and sex), age of animal at recording (linear effect), age of dam at calving (linear and quadratic effects), maternal breed composition (based on NABC definition), and individual and maternal heterozygosis (linear). In the model for PWG, 2 management groups were included in the contemporary group (weaning and yearling), and 2 ages at recording of the trait (age of the animal at weaning and yearling) were included as covariates. The random effects of direct additive genetic (all traits), maternal genetic, and maternal permanent environmental (only PWG) were also included. Further details about the basic model used and the present population of crossbreed cattle can be found in Mourão et al. $(2007,2008)$.

Genetic parameters for the study of GxE were then estimated by single- and multi-trait animal models using the AIREMLF90 program (Misztal et al., 2002) and adopting a convergence criterion of $10^{-9}$ :

1) Single-trait analysis (reduced model) when compared to single-trait analysis including the uncorrelated random effect of sire-GEO interaction (complete model). The likelihood ratio test (LRT) was used to test the significance of model $i$ (complete) containing an additional parameter when compared to model $j$, which did not include the parameter. An example is shown below for PWG:

$$
\begin{gathered}
\text { i) } y=X \beta+Z_{d} u_{d}+Z_{m} u_{m}+Z_{p} u_{p}+Z_{s g} u_{s g}+e \text { (complete) } \\
\text { j) } y=X \beta+Z_{d} u_{d}+Z_{m} u_{m}+Z_{p} u_{p}+e \text { (reduced) }
\end{gathered}
$$

where $y$ is a vector of PWG observations, $\beta$ is a vector of fixed effects (already defined above), $u_{d}$ is an unknown random vector of additive direct genetic effects, $u_{m}$ is an unknown random vector of additive maternal genetic effects, $u_{p}$ is an unknown random vector of maternal permanent environmental effects, $u_{s g}$ is an unknown random vector of sire-GEO interaction effects, and $e$ is an unknown random vector of residuals. The $X, Z_{d}, Z_{m}, Z_{p}$, and $Z_{s g}$ are known incidence matrices relating observations to $\mathrm{b}, u_{d}, u_{m}, u_{p}$, and $u_{s g}$, respectively. The covariance between direct and maternal effect was assumed to be zero.

LRT $=\left(-2 \log L_{i}\right)-\left(-2 \log L_{j}\right)$, where $L$ is the restricted likelihood function of the models.

The value obtained by the LRT was compared to that obtained by the chi-square test $\left(\chi_{\text {tab }}^{2}\right)$ with one degree of freedom. The maximum level of significance was $1 \%$. The Bayesian information criterion (BIC) was used to evaluate the goodness-of-fit of the models. The BIC was defined as follows: $\mathrm{BIC}=-2 \log L+p[\ln (N)]$, where $p$ is the number of parameters and $N$ is the number of observations. A lower BIC value indicates a better fit of the model.

2) Multi-trait analysis considering the trait studied (PWG, SC, or MUS) to be different in each GEO as proposed by Falconer (1952). The covariance between direct and maternal genetic effects for PWG and residual covariance for all traits were assumed to be zero. 


\section{Summary of data set}

Table 1 shows the summary of the data set used in all analyses.

Table 1. Description of the data set containing records of post-weaning gain (PWG), yearling scrotal circumference (SC), and yearling muscling (MUS).

\begin{tabular}{lcrr}
\hline & PWG $(\mathrm{kg})$ & SC (cm) & MUS (1 to 6) \\
\hline No. of records & 40,744 & 19,142 & 44,272 \\
No. of animals in the pedigree & 104,950 & 59,423 & 115,192 \\
No. of sires with progeny record & 276 & 217 & 307 \\
No. of dams with progeny record & 29,242 & 15,683 & 33,600 \\
No. of contemporary groups & 803 & 393 & 890 \\
Mean of the trait & 87.23 & 27.29 & 4.33 \\
SD of the trait & 45.95 & 3.95 & 1.11 \\
\hline
\end{tabular}

\section{RESULTS AND DISCUSSION}

\section{Environmental characterization and definition of the number of environments}

The R-square and RMSSTD values were 0.72 and 0.58 , respectively. The multivariate cluster technique permitted that farms located in municipalities with similar environmental conditions were grouped independent of the geographic borders of the respective states (Table 2 and Figure 1).

In the present study, most farms were located in different municipalities, a fact preventing the assigning of an identical value for a certain environmental variable to all farms belonging to the same municipality. According to Weigel and Rekaya (2000), although the herd cluster model is flexible in terms of the number and type of descriptive variables that can be used, the inclusion of irrelevant factors may lead to errors in the development of clusters. In addition, the acquisition of farm-specific information for all variables (including climate, type of soil, type of pasture, etc.) would be desirable.

As pointed out by Santana et al. (2012), GEO1, GEO2, and GEO4 had the highest mean annual temperatures, whereas medium temperatures were observed in GEO3 and GEO6 and low temperatures in GEO5 (Table 3). Compared with the other regions, GEO3 and GEO4 had the highest annual rainfall. Rainfall differed between GEOs as expected. For example, GEO4 is formed by farms located in the Amazonia biome, a region characterized by high rainfall indices, whereas GEO6 is located in a region of lower rainfall belonging to the Atlantic Rainforest biome (IBGE, 2004). Mean altitude differed between GEOs, especially between GEO3, which comprises farms located in municipalities of the Brazilian Central Plateau, and GEO6 located close to the coast line. The GEOs also differed in terms of geographic position, with clusters formed by farms located in more northern municipalities (GEO4) and those located in the south (GEO5), a fact explaining the differences in temperature and rainfall. The diversity in vegetation among the GEOs should also be mentioned, although this factor was not included as an environmental variable in the present study. The native pastures play an important role in most beef cattle production systems in Brazil. In this case, the type of local vegetation is closely related to the quality of pasture as the main feed source. The GEOs formed in the region belonging to the Pantanal and Cerrado (GEO2 and GEO3) have vegetation typical of savannah or semideciduous stationary forest, whereas Pampa is characterized by wooded or grassy-woody steppe-like vegetation (GEO5). 
Table 2. Distribution of records in the geoclimatic clusters (GEO), states and respective municipalities of the farms where the animals were raised.

\begin{tabular}{|c|c|c|c|c|c|c|c|}
\hline Identification & GEO & State & Municipality & NPWG & NSC & NMUS & Total \\
\hline 1 & 1 & SP & Araçatuba & 278 & 39 & 294 & \\
\hline 2 & 1 & SP & Guaraci & 2,362 & 442 & 3,064 & \\
\hline 3 & 1 & MS & Ivinhema & 5,197 & 1,728 & 6,034 & \\
\hline 4 & 1 & MS & Naviraí & 775 & 307 & 781 & \\
\hline 5 & 1 & SP & Pirajui & 122 & 488 & 1,247 & \\
\hline 6 & 1 & SP & Pontes Gestal & 3,252 & 1,971 & 4,976 & \\
\hline 7 & 1 & SP & Presidente Epitácio & 3,847 & 1,706 & 3,859 & \\
\hline 8 & 1 & MS & Rio Brilhante & 851 & 547 & 131 & \\
\hline 9 & 1 & GO & Santa Isabel & 449 & 223 & 379 & 45,349 \\
\hline 10 & 2 & MS & Anastácio & 203 & 159 & 180 & \\
\hline 11 & 2 & MS & Dois Irmãos do Buriti & 1,468 & 60 & 2,055 & \\
\hline 12 & 2 & MS & Miranda & 1,477 & 497 & 184 & \\
\hline 13 & 2 & MS & Santa Rita do Pardo & 3,604 & 1,116 & 3,181 & 14,184 \\
\hline 14 & 3 & $\mathrm{GO}$ & Aporé & 1,097 & 1,168 & 1,338 & \\
\hline 15 & 3 & GO & Britânia & 518 & 183 & 593 & \\
\hline 16 & 3 & MT & Comodoro & 168 & 145 & 145 & \\
\hline 17 & 3 & MS & Jaraguari & - & 160 & 525 & \\
\hline 18 & 3 & GO & Jataí & 1,107 & 332 & 1,144 & \\
\hline 19 & 3 & MS & Laguna Carapa & 1,461 & 1,096 & 2,631 & \\
\hline 20 & 3 & GO & Mutunópolis & 1,311 & 422 & 133 & \\
\hline 21 & 3 & MS & Ponta Porã & 1,280 & 449 & 1,417 & 18,823 \\
\hline 22 & 4 & MT & Alta Floresta & 2,647 & 1,779 & 2,713 & \\
\hline 23 & 4 & RO & Ariquemes & 832 & 451 & 390 & \\
\hline 24 & 4 & PA & Cumaru do Norte & 290 & 310 & 290 & 9,702 \\
\hline 25 & 5 & $\mathrm{RS}$ & Pelotas & 1,351 & 752 & 1,242 & \\
\hline 26 & 5 & RS & Santana do Livramento & 990 & 938 & 945 & 6,218 \\
\hline 27 & 6 & MG & Carlos Chagas & 3,807 & 1,674 & 4,401 & 9,882 \\
\hline Total & & & & 40,744 & 19,142 & 44,272 & 104,158 \\
\hline
\end{tabular}

$\mathrm{NPWG}=$ No. of records for post-weaning gain; NSC $=$ No. of records for yearling scrotal circumference; NMUS = No. of records for yearling muscling; $\mathrm{GO}=$ Goiás; $\mathrm{MG}=$ Minas Gerais; $\mathrm{MS}=$ Mato Grosso do Sul; MT = Mato Grosso; PA = Pará; RS = Rio Grande do Sul; SP = São Paulo.

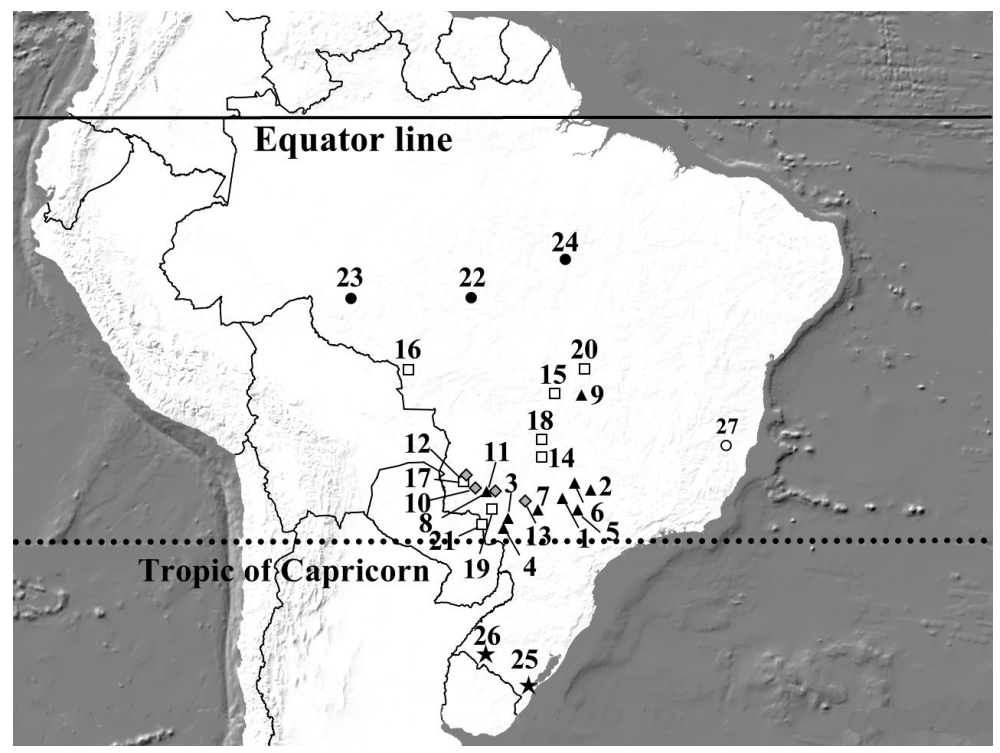

Figure 1. Location of the municipalities (according to the identification in Table 2) where the farms of origin of the animals were situated (black triangle $=\mathrm{GEO} 1$; gray diamond $=\mathrm{GEO} 2$; white square $=\mathrm{GEO} 3$; black circle $=\mathrm{GEO} 4$; black star $=$ GEO5; white circle $=$ GEO6). 
Table 3. Mean environmental variables \pm standard deviations obtained from each geoclimatic cluster (GEO) formed.

\begin{tabular}{lcccccc}
\hline GEO & Lat $\left({ }^{\circ}\right)$ & Lon $\left({ }^{\circ}\right)$ & $\mathrm{R}(\mathrm{mm})$ & $\mathrm{A}(\mathrm{m})$ & $\operatorname{MINT}\left({ }^{\circ} \mathrm{C}\right)$ & $\operatorname{MAXT}\left({ }^{\circ} \mathrm{C}\right)$ \\
\hline 1 & $21.26 \pm 2.28$ & $51.67 \pm 2.27$ & $1,291.56 \pm 75.77$ & $391.03 \pm 96.56$ & $17.35 \pm 0.71$ & $30.17 \pm 0.83$ \\
2 & $20.92 \pm 0.45$ & $54.12 \pm 1.56$ & $1,158.33 \pm 56.97$ & $277.57 \pm 116.07$ & $19.33 \pm 0.20$ & $30.85 \pm 0.11$ \\
3 & $19.38 \pm 3.61$ & $53.29 \pm 3.31$ & $1,515.27 \pm 172.41$ & $534.78 \pm 139.88$ & $16.95 \pm 0.57$ & $28.46 \pm 0.43$ \\
4 & $9.52 \pm 1.28$ & $56.63 \pm 6.29$ & $1,818.20 \pm 132.73$ & $259.91 \pm 86.39$ & $18.53 \pm 0.56$ & $30.19 \pm 1.41$ \\
5 & $31.28 \pm 0.62$ & $54.10 \pm 2.26$ & $1,334.38 \pm 89.23$ & $123.01 \pm 135.05$ & $14.92 \pm 1.24$ & $25.20 \pm 2.82$ \\
$6^{*}$ & 17.70 & 40.76 & $1,019.77$ & 159.00 & 17.33 & 28.66 \\
\hline \multicolumn{7}{l}{ Lat $=$ latitude; Lon = longitude; $\mathrm{R}=$ annual rainfall; $\mathrm{A}=$ altitude; MINT = minimum annual temperature; MAXT $=$} \\
\multicolumn{5}{l}{}
\end{tabular}

\section{Estimating genetic parameters to study genotype by environment interaction}

\section{Single-trait analysis}

The lowest BIC values indicate the most adequate models; thus, the models including the effect of sire-GEO for PWG and MUS should be preferred for genetic evaluation (Table 4). In the present study, the differences between the complete and reduced models for PWG and MUS were 64.23 and 101.72, respectively. The result of the LRT was -76.22 for PWG, -3.57 for SC, and -112.51 for MUS and was significant at the 1\% level for PWG and MUS. These results demonstrate the importance of applying a more complex model to the genetic evaluation of PWG and MUS in this population. As can be seen, omission of the effect of sire-GEO interaction overestimates the additive genetic variance for PWG and MUS by 25 and $10 \%$, respectively, consistent with observations by Bertrand et al. (1987).

Table 4. Estimates of variance components, heritability, standard erros in parentheses, logarithm of the restricted likelihood function $(-2 \log L)$, and Bayesian information criterion (BIC) from complete and reduced models for the traits studied of composite beef cattle.

\begin{tabular}{|c|c|c|c|c|c|c|}
\hline & Post-wean & in $(\mathrm{kg})$ & Yearling scro & mference $(\mathrm{cm})$ & Yearling 1 & $\lg (1$ to 6$)$ \\
\hline & Reduced & Complete & Reduced & Complete & Reduced & Complete \\
\hline$\sigma_{a}^{2}$ & $48.58(0.21)$ & $36.06(0.01)$ & $2.29(0.00)$ & $2.22(0.01)$ & $0.10(0.00)$ & $0.09(0.00)$ \\
\hline$\sigma_{s g}^{2}$ & - & $10.46(0.01)$ & - & $0.04(0.00)$ & - & $0.01(0.00)$ \\
\hline$\sigma_{m}^{2}$ & $15.76(0.01)$ & $16.50(0.01)$ & - & - & - & - \\
\hline$\sigma_{m p}^{2}$ & $8.38(0.01)$ & $8.54(0.01)$ & - & - & - & - \\
\hline$\sigma_{e}^{2}$ & $445.60(3.08)$ & $449.70(0.01)$ & $7.29(0.01)$ & $7.32(0.01)$ & $0.53(0.00)$ & $0.54(0.00)$ \\
\hline & $0.09(0.00)$ & $0.07(0.00)$ & $0.24(0.00)$ & $0.23(0.00)$ & $0.16(0.00)$ & $0.14(0.00)$ \\
\hline$h_{m}^{2}$ & $0.03(0.00)$ & $0.03(0.00)$ & - & - & - & - \\
\hline$c^{2}$ & $0.01(0.00)$ & $0.01(0.00)$ & - & - & - & - \\
\hline$s g^{2}$ & - & $0.02(0.00)$ & - & $0.00(0.00)$ & - & $0.01(0.00)$ \\
\hline$-2 \log L$ & $301.01^{\mathrm{a}}$ & $224.79^{\mathrm{a}}$ & $831.18^{\mathrm{b}}$ & $827.60^{\mathrm{b}}$ & $395.74^{\circ}$ & $283.23^{\mathrm{c}}$ \\
\hline $\mathrm{BIC}$ & $320.95^{\mathrm{a}}$ & $256.72^{\mathrm{a}}$ & $850.90^{\mathrm{b}}$ & $857.18^{\mathrm{b}}$ & $417.31^{\circ}$ & $315.59^{\mathrm{c}}$ \\
\hline
\end{tabular}

$\sigma_{a}^{2}=$ direct additive genetic variance, $\sigma_{s g}^{2}=$ sire-geoclimatic group interaction variance, $\sigma_{m}^{2}=$ maternal additive genetic variance, $\sigma_{m p}^{2}=$ maternal permanent environmental variance, $\sigma_{e}^{2}=$ residual variance, $h_{d}^{2}=$ heritability for direct additive genetic effects, $h_{m}^{2}=$ heritability for maternal additive genetic effects, $c^{2}=$ maternal permanent environmental effect as proportion of phenotypic variance, $\mathrm{sg}^{2}=$ sire-geoclimatic group interaction effect as a proportion of phenotypic variance; $\mathrm{a}=+274,000 ; \mathrm{b}=+120,000 ; \mathrm{c}=+165,000$. 
The heritability estimates for PWG obtained in the present study were lower than those reported in the literature. Marcondes et al. (2000) obtained a heritability estimate of 0.18 for Nellore animals (Brazil), and Cardoso et al. (2004) reported an estimate of 0.20 for Angus cattle (Brazil). These wide variations in the heritability estimates for this trait are probably due in part to difference between breeds, management systems, and rearing environments.

Our heritability estimates for SC were lower than those reported in the literature, but still indicated that this trait will respond to selection (Table 4). Burrow (2001) and Eler et al. (2004) reported a heritability for yearling SC of 0.37 in a composite breed of tropical beef cattle and 0.57 in purebred Nellore. The heritability estimates for MUS were similar to those reported by Shiotsuki et al. (2009) and Santana et al. (2010), who obtained estimates of 0.23 for Brazilian Nellore and 0.12 to 0.18 for part of the present population.

\section{Multi-trait analysis}

The differences in estimates of heritability for PWG, SC, and MUS demonstrated the existence of genetic variation between the GEOs studied, a fact that suggests a different response to selection depending on the rearing environment of the animals (Table 5). These differences between heritability estimates reflect heterogeneity of variances and were reported by Weigel and Rekaya (2000) and Zwald et al. (2003) in studies on dairy cattle and by Nephawe et al. (1996), Ibi et al. (2005), and Lopes et al. (2008) in studies on beef cattle. According to DeNise et al. (1988) and Toral et al. (2004), a trait may be influenced by sets of different genes in distinct environments and these genes may be expressed at variable levels according to the degree of similarity or difference within or between environments.

Table 5. Estimates of variance components (standard erros in parentheses) for post-weaning weight (PWG), yearling scrotal circumference (SC) and yearling muscling (MUS) of composite beef cattle in different environments in Brazil.

\begin{tabular}{|c|c|c|c|c|c|c|c|c|}
\hline \multirow[t]{3}{*}{ GEO } & \multicolumn{8}{|c|}{ Traits } \\
\hline & \multicolumn{4}{|c|}{ PWG (kg) } & \multicolumn{2}{|c|}{$\mathrm{SC}(\mathrm{cm})$} & \multicolumn{2}{|c|}{ MUS ( 1 to 6 ) } \\
\hline & $\sigma_{a}^{2}$ & $\sigma_{m}^{2}$ & $\sigma_{m p}^{2}$ & $\sigma_{e}^{2}$ & $\sigma_{a}^{2}$ & $\sigma_{e}^{2}$ & $\sigma_{a}^{2}$ & $\sigma_{e}^{2}$ \\
\hline 1 & $52.41(0.22)$ & $18.30(0.01)$ & $4.23(0.01)$ & $420.31(2.90)$ & $2.31(0.00)$ & $7.15(0.01)$ & $0.10(0.01)$ & $0.50(0.00)$ \\
\hline 2 & $53.64(0.23)$ & $1.75(0.00)$ & $2.16(0.00)$ & $373.53(2.58)$ & $2.70(0.01)$ & $5.81(0.01)$ & $0.13(0.00)$ & $0.59(0.01)$ \\
\hline 3 & $107.82(0.47)$ & $3.93(0.01)$ & $3.34(0.01)$ & $512.23(3.54)$ & $2.57(0.01)$ & $7.88(0.02)$ & $0.10(0.00)$ & $0.59(0.02)$ \\
\hline 4 & $103.11(0.45)$ & $2.20(0.00)$ & $2.18(0.00)$ & $457.32(3.16)$ & $1.57(0.00)$ & $7.56(0.02)$ & $0.14(0.01)$ & $0.45(0.01)$ \\
\hline 5 & $57.68(0.25)$ & $1.97(0.00)$ & $1.91(0.00)$ & $541.12(3.74)$ & $1.89(0.01)$ & $6.00(0.02)$ & $0.11(0.02)$ & $0.57(0.01)$ \\
\hline 6 & $93.82(0.40)$ & $2.14(0.00)$ & $1.79(0.00)$ & $414.50(2.86)$ & $2.70(0.01)$ & $7.87(0.01)$ & $0.09(0.00)$ & $0.41(0.00)$ \\
\hline
\end{tabular}

For PWG, the lowest heritability estimates were observed in GEO5 (representing the extreme south of Brazil). This finding might be explained by inadequate management practices during the post-weaning period or an unfavorable environment for animal growth, conditions that compromise the expression of the genetic potential of the animals (Table 6). The highest heritability was observed in GEO4 and GEO6, indicating that the environmental conditions in these regions favor the expression of genetic differences. According to Falconer and 
Mackay (1996), heritability is a property of the population and of the environment to which the animal is exposed, whereas environmental variance depends on production and management conditions: greater environmental variation reduces heritability, and a more homogenous environment increases heritability.

\begin{tabular}{|c|c|c|c|c|c|c|c|}
\hline & GEO & 1 & 2 & 3 & 4 & 5 & 6 \\
\hline \multirow[t]{8}{*}{ PWG } & 1 & $0.10(0.01)$ & $0.83(0.02)$ & $0.31(0.05)$ & $0.49(0.06)$ & $0.69(0.09)$ & $0.62(0.05)$ \\
\hline & 2 & & $0.13(0.02)$ & $0.67(0.10)$ & $0.81(0.06)$ & $0.90(0.07)$ & $0.86(0.06)$ \\
\hline & 3 & & & $0.19(0.03)$ & $0.89(0.06)$ & $0.80(0.08)$ & $0.80(0.12)$ \\
\hline & 4 & & & & $0.20(0.04)$ & $0.89(0.10)$ & $0.93(0.11)$ \\
\hline & 5 & & & & & $0.04(0.00)$ & $0.91(0.09)$ \\
\hline & 6 & & & & & & $0.20(0.04)$ \\
\hline & 1 & $0.24(0.02)$ & $0.89(0.08)$ & $0.82(0.08)$ & $0.71(0.11)$ & $0.81(0.03)$ & $0.85(0.04)$ \\
\hline & 2 & & $0.31(0.04)$ & $0.80(0.07)$ & $0.65(0.13)$ & $0.80(0.15)$ & $0.79(0.05)$ \\
\hline \multirow[t]{6}{*}{$\mathrm{SC}$} & 3 & & & $0.24(0.03)$ & $0.73(0.12)$ & $0.74(0.16)$ & $0.80(0.11)$ \\
\hline & 4 & & & & $0.17(0.01)$ & $0.64(0.09)$ & $0.66(0.09)$ \\
\hline & 5 & & & & & $0.23(0.03)$ & $0.77(0.07)$ \\
\hline & 6 & & & & & & $0.25(0.02)$ \\
\hline & 1 & $0.17(0.02)$ & $0.80(0.04)$ & $0.76(0.11)$ & $0.59(0.12)$ & $0.28(0.09)$ & $0.35(0.07)$ \\
\hline & 2 & & $0.18(0.03)$ & $0.80(0.08)$ & $0.53(0.07)$ & $0.30(0.09)$ & $0.42(0.08)$ \\
\hline \multirow{4}{*}{ MUS } & 3 & & & $0.14(0.02)$ & $0.58(0.08)$ & $0.34(0.11)$ & $0.35(0.08)$ \\
\hline & 4 & & & & $0.24(0.03)$ & $0.35(0.13)$ & $0.49(0.6)$ \\
\hline & 5 & & & & & $0.17(0.02)$ & $0.18(0.04)$ \\
\hline & 6 & & & & & & $0.18(0.03)$ \\
\hline
\end{tabular}

$\mathrm{GEO}=$ geoclimatic cluster.

According to Robertson (1959), genetic correlations of lower than 0.80 indicate the existence of GxE. For PWG, GxE was more pronounced between GEO1-GEO3, GEO1GEO4, and GEO2-GEO3. Thus, breeders should be aware of the re-ranking of sires across these regions. In a study on Hereford cattle, DeNise and Torabi (1989) observed that genetic parameters for weight and PWG change in response to the environment and differ between sexes, which can cause inaccurate estimation of parameters if these factors are not considered. The authors also suggest that additional evaluation of productive traits in unfavorable environments may be useful for refining sire evaluations.

As an example of the consequences of GxE interactions, Table 7 shows the percentage of sires selected in common when different proportions of individuals are selected $(b)$ for PWG in GEO1 and in the other regions.

As can be seen in the table, fewer sires are selected in common for PWG in GEO1 (Cerrado and Pantanal) and in the other regions, especially when a lower $b$ is applied. Therefore, under lower $b$, the appropriate sires for a certain region are not the same as for the other regions, even in those regions where no significant GxE was found previously (e.g., between GEO1 and GEO2).

The lowest heritability for $\mathrm{SC}$ was observed in GEO4, which comprises farms located in municipalities of the hot and humid region of Brazil. This estimate can be explained by the fact that this trait is negatively influenced by temperature and humidity (Nelsen et al., 1986; Godfrey et al., 1990). Godfrey et al. (1990) found that testis size of Hereford bulls was smaller in the hottest months and larger in the coldest months of the year. These authors also observed a marked influence of photoperiod on testicular growth. Variation in the photoperiod 
over the year is less pronounced in GEO4 when compared to the other regions. Since SC is a trait indicative of sperm production and quality (Bourdon and Brinks, 1986; Eler et al., 2004), the reproductive function of animals may be compromised in tropical environments unless adequate management practices are applied.

Table 7. Percentage of sires (with at least 20 progeny records) selected in common when different proportions (b) of individuals are selected for post-weaning gain in geoclimatic cluster 1 (GEO1) and in the other clusters.

\begin{tabular}{rccccc}
\hline $\mathrm{b}(\%)$ & GEO1-GEO2 & GEO1-GEO3 & GEO1-GEO4 & GEO1-GEO5 & GEO1-GEO6 \\
\hline 1 & 60 & 20 & 20 & 60 & 40 \\
5 & 63 & 21 & 42 & 58 & 68 \\
10 & 78 & 36 & 50 & 76 & 60 \\
20 & 83 & 43 & 61 & 83 & 71 \\
40 & 85 & 60 & 71 & 91 & 77 \\
60 & 100 & 76 & 83 & & 87 \\
\hline
\end{tabular}

Although the LRT showed no significant GxE interaction in single-trait analysis, according to the criterion of Robertson (1959), multi-trait analysis indicated the presence of a GxE interaction for SC between some GEOs. In view of the environmental diversity evident among GEOs, an environmental influence on the expression of this trait should not be ruled out. Thus, the use of different methods for the investigation of the presence or absence of this interaction is important.

Similar to PWG, GEO4 presented the highest heritability estimate for MUS. The combination of high temperature and rainfall seems to favor the expression of MUS, providing more adequate environmental conditions such as forage growth. The genetic correlations for MUS showed the existence of a GxE interaction for this trait. According to the criterion of Robertson (1959), this interaction was more expressive between GEO5 and GEO6 (extreme south and southeast of Brazil, respectively) and the other regions, i.e., the best animals in terms of MUS of a certain region are generally not the same for the other regions.

\section{CONCLUSIONS}

The GxE interaction is an important factor to be included in genetic evaluations for the studied population. The use of multivariate analysis for grouping of herds is feasible and useful to simplify environments. The proper consideration of variables that best describe the environment of each herd is a key point. The low genetic correlations between regions indicate the need for a genetic analysis on a regional basis or inclusion of the GxE effect in the statistical model to permit appropriate evaluation of the animals.

\section{ACKNOWLEDGMENTS}

We thank Fundação de Amparo à Pesquisa do Estado de São Paulo (FAPESP) for the fellowship granted to M.L. Santana Jr. (\#2009/05072-4) and the government funding agency Conselho Nacional de Desenvolvimento Científico e Tecnológico (CNPq). We are also indebted to CFM-Leachman Pecuária Ltda. for providing access to the database used in this study. The authors acknowledge the technical assistance of Dr. Shogo Tsuruta (University of Georgia). 


\section{REFERENCES}

Agritempo (2009). Sistema de Monitoramento Agrometeorológico. Available at [http://www.agritempo.gov.br]. Accessed August 15, 2009.

Bertrand JK, Hough JD and Benyshek LL (1987). Sire x environment interactions and genetic correlations of sire progeny performance across regions in dam-adjusted field data. J. Anim. Sci. 64: 77-82.

Bourdon RM and Brinks JS (1986). Scrotal circumference in yearling Hereford bulls: adjustment factors, heritabilities and genetic, environmental and phenotypic relationships with growth traits. J. Anim. Sci. 62: 958-967.

Burrow HM (2001). Variances and covariances between productive and adaptive traits and temperament in a composite breed of tropical beef cattle. Livest. Prod. Sci. 70: 213-233.

Cardoso FF, Cardellino RA and Campos LT (2004). (Co)variance components and genetic parameters of post-weaning traits in Angus cattle. R. Bras. Zootec. 33: 313-319.

DeNise SK and Torabi M (1989). Genetic parameter estimates for postweaning traits of beef cattle in a stressful environment. J. Anim. Sci. 67: 2619-2626.

DeNise SK, Torabi M, Ray DE and Rice R (1988). Genetic parameter estimates for preweaning traits of beef cattle in a stressful environment. J. Anim. Sci. 66: 1899-1906.

Eler JP, Ferraz JBS, Golden BL and Pereira E (2000). Influence of sire $\mathrm{x}$ herd interaction on the estimation of correlation between direct and maternal genetic effects in Nellore cattle. R. Bras. Zootec. 29: 1642-1648.

Eler JP, Silva JA, Evans JL, Ferraz JB, et al. (2004). Additive genetic relationships between heifer pregnancy and scrotal circumference in Nellore cattle. J. Anim. Sci. 82: 2519-2527.

Falconer DS (1952). The problem of environment and selection. Am. Nat. 86: 293.

Falconer DS and Mackay TFC (1996). Introduction to Quantitative Genetics. 4th edn. Longman Group, Harlow.

Ferraz JBS, Eler JP and Golden BL (1999). A formação do composto montana tropical. Rev. Bras. Reprod. Anim. 23: 115-117.

Godfrey RW, Lunstra DD, Jenkins TG, Berardinelli JG, et al. (1990). Effect of location and season on body and testicular growth in Brahman and Hereford bulls. J. Anim. Sci. 68: 1520-1529.

IBGE (2004). Mapa de Biomas e Vegetação do Brasil. Available at [http://www.ibge.gov.br]. Accessed August 25, 2010.

Ibi T, Hirooka H, Kahi AK, Sasae Y, et al. (2005). Genotype x environment interaction effects on carcass traits in Japanese Black cattle. J. Anim. Sci. 83: 1503-1510.

Khattree R and Naik DN (2000). Multivariate Data Reduction and Discrimination with SAS Software. SAS Institute, Cary.

Lopes JS, Rorato PRN, Weber T and Boligon AA (2008). Genotype and environment interaction effect on weights at birth, 205 and550 days of age of Nellore cattle in the South Region of Brazil. R. Bras. Zootec. 37: 54-60.

Marcondes CR, Bergmann JAG, Eler JP and Ferraz JBS (2000). Analysis of some selection criteria for growth traits in Nellore cattle. Arq. Bras. Med. Vet. Zootec. 52: 83-89 52: 83-89.

Misztal I, Tsuruta S, Strable T and Auvray B (2002). BLUPF90 and Related Programs (BGF90). CD-ROM Communication 28:07 in Proceeding of the 7th World Congress, Montpellier.

Mourão GB, Ferraz JB, Eler JP, Balieiro JC, et al. (2007). Genetic parameters for growth traits of a Brazilian Bos taurus x Bos indicus beef composite. Genet. Mol. Res. 6: 1190-1200.

Mourão GB, Ferraz JB, Eler JP, Bueno RS, et al. (2008). Non-additive genetic effects on weights and performance of a Brazilian Bos taurus x Bos indicus beef composite. Genet. Mol. Res. 7: 1156-1163.

Nelsen TC, Short RE, Urick JJ and Reynolds WL (1986). Heritabilities and genetic correlations of growth and reproductive measurements in Hereford bulls. J. Anim. Sci. 63: 409-417.

Nephawe KA, Neser FWC, Roux CZ and Theron HE (1996). The inclusion of herd-year-season by sire interaction in the estimation of genetic parameters in Bonsmara cattle. S. Afr. J. Anim. Sci. 26: 75-78.

Ravagnolo O and Misztal I (2002). Studies on genetics of heat tolerance in dairy cattle with reduced weather information via cluster analysis. J. Dairy Sci. 85: 1586-1589.

Robertson A (1959). The sampling variance of the genetic correlation coefficient. Biometrics 15: 469-485.

Santana ML Jr, Pedrosa VB, Groeneveld E and Ferraz JBS (2010). Genotype x Environment Interaction for Growth and Reproduction Traits of Composite Beef Cattle in Brazil. CD-ROM Communication 0162 in Proceedings of the 9th World Congress, Leipzig.

Santana ML Jr, Eler JP, Cardoso FF and Albuquerque LG (2012). Genotype by environment interaction for birth and weaning weights of composite beef cattle in different regions of Brazil. Livest. Sci. 149: 242-249.

SAS (2008). User's Guide: Statistics. Version 9.2 Edition. SAS Inst, Cary.

Shiotsuki L, Silva JA, Tonhati H and Albuquerque LG (2009). Genetic associations of sexual precocity with growth traits and visual scores of conformation, finishing, and muscling in Nelore cattle. J. Anim. Sci. 87: 1591-1597.

Tess MW, Jeske KE, Dillard EU and Robison OW (1984). Sire x environment interactions for growth traits of Hereford 
cattle. J. Anim. Sci. 59: 1467-1476.

Toral FLB, Silva LOC, Martins EN, Gondo A, et al. (2004). Genotype x environment interaction in growth traits of Nellore cattle of Mato Grosso do Sul. R. Bras. Zootec. 33: 1445-1455.

Weigel KA and Rekaya R (2000). A multiple-trait herd cluster model for international dairy sire evaluation. J. Dairy Sci. 83: 815-821.

Zwald NR, Welgel KA, Fikse WF and Rekaya R (2003). Application of a multiple-trait herd cluster model for genetic evaluation of dairy sires from seventeen countries. J. Dairy Sci. 86: 376-382. 